
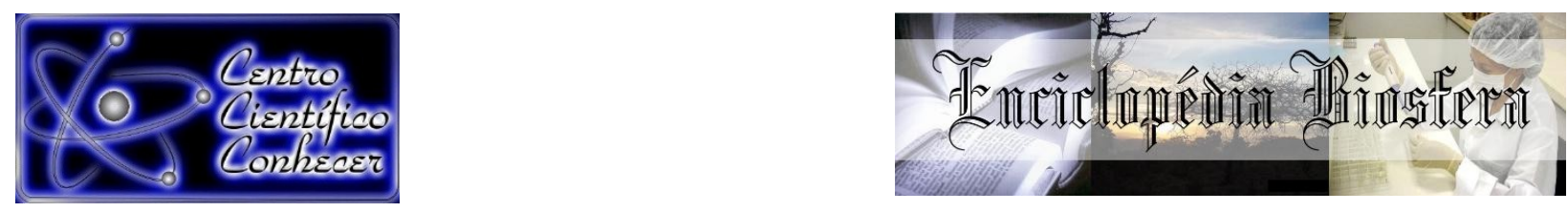

\title{
INTRODUÇÃO E REAVALIAÇÃO DE AECHMEA BROMELIIFOLIA (RUDGE) BAKER PARA FINS DE ENRIQUECIMENTO EM AREA RESTAURADA NO BIOMA CERRADO
}

Rodrigo Faleiro ${ }^{1}$, Fernanda Duarte ${ }^{2}$, Caio Calassa ${ }^{3}$, Juliane Cruz Barros ${ }^{4}$, Sybelle Barreira ${ }^{5}$,

${ }^{1}$ Engenheiro Florestal (UFG), Pavilhão de Horticultura (ESALQ/USP), Piracicaba-SP. ${ }^{2}$ Engenheira Florestal, Goiânia-GO.

${ }^{3}$ Engenheiro Florestal, Goiânia-GO.

${ }^{4}$ Discente de Engenharia Florestal (UFG), Goiânia-GO.

${ }^{5}$ Doutora em Recursos Florestais (ESALQ/USP), Docente de Engenharia Florestal (UFG), Goiânia-GO, E-mail: sybelle.barreira@gmail.com

Recebido em: 15/02/2020 - Aprovado em: 15/03/2020 - Publicado em: 30/03/2020

DOI: 10.18677/EnciBio_2020A11

\begin{abstract}
RESUMO
A restauração florestal é a ciência, prática e arte de assistir e manejar à recuperação da integridade ecológica dos ecossistemas, incluindo um nível mínimo de biodiversidade e de variabilidade na estrutura e funcionamento dos processos ecológicos e, dentre outras técnicas tem-se o enriquecimento que consiste na introdução de espécies para aumento da diversidade. O presente trabalho buscou introduzir e monitorar a espécie Aechmea bromelifolia (Rudge) Baker em área restaurada no Cerrado. Foram reavaliados 18 indivíduos, em três forófitos diferentes (Jacaranda cuspidifolia Mart., Anadenanthera falcata (Benth.) Speg., Sapindus saponaria L.) e introduzidas e avaliadas mais dez indivíduos em dois forófitos distintos (Dipteryx alata Vogel e Caryocar brasiliense Cambess), quantificando-se a produção de folhas e a intensidade de luz incidente no local. Os indivíduos avaliados tiveram bom desenvolvimento na maioria dos forófitos, sendo Jacaranda cuspidifolia Mart. que promoveu o melhor desenvolvimento. A taxa de mortalidade nos indivíduos introduzidos foi nula demonstrando que a espécie estudada apresenta alta adaptabilidade. Não foi encontrada correlação entre a intensidade luminosa e a produção de folhas, demonstrando que o sombreamento pode não ter sido prejudicial. Foi possível a observação de processos ecológicos como a polinização, abrigo para fauna e a ciclagem de nutrientes. Desta forma o enriquecimento com bromélias se mostra eficiente para áreas restauradas e pode colaborar minimamente com os processos ecológicos locais.
\end{abstract}

PALAVRAS-CHAVE: enriquecimento, bromélias, processos ecológicos

\section{INTRODUCTION AND RE-EVAALUATION OF AECHMEA BROMELIFOLIA (RUDGE) BAKER FOR ENRICHMENT IN RESTORED AREAS}

\footnotetext{
ABSTRACT

Forest restoration is the science, practice and art of assisting and managing the recovery of ecological integrity of ecosystems, including a minimum level of biodiversity and variability in the structure and functioning of ecological processes
} 
and, among other techniques, there is the enrichment that consists introducing species to increase diversity. The present work sought to introduce and monitor the species Aechmea bromelifolia (Rudge) Baker in a restored area in the Cerrado. Eighteen individuals were reevaluated in three different phorophytes (Jacaranda cuspidifolia Mart., Anadenanthera falcata (Benth.) Speg., Sapindus saponaria L.) and another ten individuals were introduced and evaluated in two different phorophytes (Dipteryx alata Vog. and Caryocar brasiliense Cambees.), quantifying a leaf production and the intensity of light incident on the site. The evaluated individuals had good development in most of the forophytes, being Jacaranda cuspidifolia Mart. that promoted the best development. The mortality rate in the individuals was low, showing good adaptability of the studied species. No correlation was found between light intensity and leaf production, demonstrating that shading may not have been harmful. It was possible to observe ecological processes such as pollination, fauna shelter and nutrient cycling. In this way, enrichment with bromeliads is efficient for restored areas and can minimally collaborate with local ecological processes.

KEYWORDS: enrichment, bromeliads, ecological processes

\section{INTRODUÇÃO}

No Brasil desde o século XIX, tem se estabelecido plantações florestais por diferentes razões, seja para o mercado de celulose, energia, madeira sólida e para recuperação de áreas degradadas, que desponta como um importante desafio a ser superado. Entretanto, somente na década de 1980, com o desenvolvimento da ecologia de restauração como ciência, o termo restauração ecológica e suas derivações passaram a ser mais claramente definidos (CURY; JR, 2011).

A degradação ambiental no Brasil e, em especial no Cerrado, decorrente da expansão da agropecuária, tem transformado consideravelmente o seu perfil, resultando em excesso de desmatamento, compactação do solo, erosão, assoreamento de rios, contaminação da água subterrânea, e perda de biodiversidade, com reflexos sobre todo o ecossistema. As principais atividades econômicas estão associadas à atividade de agricultura anual e perene, (baseada na grande propriedade, na monocultura e em processos de fertilização química) e na utilização do território para pastagem, aspectos estes que contribuem para a perda de vegetação natural (CAVALCANTE, 2019).

A fragmentação de ecossistemas naturais decorre, sobretudo, da ampliação de áreas agrícolas, resultando em isolamento dos habitats remanescentes, comprometendo a dispersão de sementes e a regeneração da vegetação (MAGNAGO et al., 2012). Em muitos casos, a intervenção do homem é necessária para estabilizar e reverter os processos de degradação, acelerando e direcionando a sucessão por meio da restauração ecológica, que visa restabelecer forma e função aos ambientes degradados, considerando os valores ecológicos, ambientais e sociais.

Dentro dessa ciência são encontrados diversos métodos, sendo um deles, o enriquecimento, que consiste na introdução de espécies em áreas com melhores condições de solo e já com presença de vegetação nativa, porém com baixa diversidade de espécies, visando aumentar a biodiversidade aos níveis naturalmente encontrados no ecossistema de referência, sendo uma destas espécies as epífitas como as bromélias e orquídeas. Plantas epífitas desempenham papel importante na diversidade de dosséis florestais e recursos essenciais em sistemas agroflorestais (DAROCHA et al., 2015). 
A interação biótica entre epifíticas e sua árvore hospedeira é conhecida como comensalismo, onde o forófito não é afetado negativamente enquanto provê suporte físico para as epífitas que se beneficiam com condições favoráveis ao seu crescimento (BENZING, 1990). Essa condição, no entanto, pode se alterar quando de alguma forma o forófito sofre danos mecânicos ou até mesmo inibição da fotossíntese provocada pelo excesso de plantas epífitas (MONTANA et al., 1997).

As bromeliáceas possuem grande versatilidade por conta de seu alto grau de adaptação a ambientes rochosos, de solos pobres, em situações distintas de intensidade de radiação solar direta, bem como a interiores de matas (GERBER et al., 2017).

Aechmea bromeliifolia (Rudge) Baker pertence à família Bromeliaceae, adaptadas ao epifítismo, apresentando importância ecológica, devido à capacidade de armazenamento de água no tanque, atuando como refúgio contra predadores ou para reprodução. Também conhecida como gravatá de tingir, possui cerca de 50 a $100 \mathrm{~cm}$ de altura, com inflorescência simples, espigada, fértil, elipsoide ou cilíndrica, com flores amarelos esverdeados (MOLIZANE et al., 2013). A anatomia foliar da espécie já foi descrita, apresentando tricomas glandulares estratificados, cutícula fina, folha hipoestomática e mesofilo contendo parênquima aquífero e colênquima (SILVA et al., 2020). Pertencente a Bromelioideae (Bromeliaceae), se distribui em praticamente todos os estados brasileiros. Ocorre em diferentes tipos de vegetação, como campo rupestre, cerrado latu sensu, floresta ciliar ou de galeria, floresta estacional semidecidual e floresta ombrófila (FORZZA et al., 2016).

Dessa forma, o presente trabalho teve como objetivo avaliar a sobrevivência e desenvolvimento dos indivíduos introduzidos de Aechmea bromelifoliia (Rudge) Baker no ano de 2016 e a introdução de novos indivíduos da mesma espécie em forófitos distintos, buscando verificar a sobrevivência e adaptação desta espécie em diferentes hospedeiros.

\section{Localização da área de estudo}

\section{MATERIAL E MÉTODOS}

A área de estudo está situada na Universidade Federal de Goiás, Campus Samambaia, Escola de Agronomia (16 $35^{\prime} \mathrm{S}, 4^{\circ} 29^{\prime} \mathrm{W}$ e $730 \mathrm{~m}$ de altitude), no município de Goiânia - GO. Segundo a classificação de Köppen, o clima da região é do tipo Aw (quente e semiúmido, com estação seca bem definida nos meses de maio a outubro). A temperatura média anual é de $23,2^{\circ} \mathrm{C}$, com média mínima anual de $17,9^{\circ} \mathrm{C}$. A precipitação média anual da região é de $1759,9 \mathrm{~mm}$.

\section{Material botânico}

As mudas de $A$. bromelifoliia foram adquiridas no Viveiro-Escola do curso de Engenharia Florestal da UFG, produzidas via sementes oriundas de doação e coletadas na Cidade de Goiás - GO, com a utilização de substrato composto por terra $25 \%$ + Areia $25 \%$ + Húmus de minhoca $25 \%$ + pó de cascas (fibra de coco, casca de pinheiro e serragem decomposta).

Implantação dos indivíduos

As mudas foram fixadas pelo rizoma e pelas folhas a troncos verticais dos forófitos, a aproximadamente 1,5 de altura, e nas bifurcações do fuste, utilizando tecido TNT nas dimensões de $1 \mathrm{~m}$ x 0,2 m, no mês de outubro/2016.

Foram introduzidos 18 indivíduos de Aechmea bromelifoliia na área após apresentar três folhas, em três espécies arbóreas diferentes (Jacaranda cuspidifolia 
Mart., Anadenanthera falcata (Benth.) Speg. e Sapindus saponaria L.), que servem como forófitos para as bromélias, elas foram dispostas em posições distintas (fuste retilíneo e na bifurcação), a fim de se verificar a melhor adaptação dessas espécies. Foram inseridos seis indivíduos de $A$. bromelifoliia para cada espécie arbórea, sendo três inseridos no fuste retilíneo e três na bifurcação.

Num segundo momento foram introduzidos mais 10 indivíduos, com cinco folhas cada um no mês de outubro de 2017, utilizando-se de duas novas espécies como forófitos (Dipteryx alata Vogel. e Caryocar brasiliense Cambees.), cinco em cada espécie.

Para a introdução das novas bromélias, estas foram retiradas do saco plástico aonde estavam sendo cultivadas, optando-se por manter o substrato, diferentemente dos primeiros indivíduos, a fim de deixar uma fonte de nutrientes e manter a umidade das raízes. Para a fixação dos indivíduos utilizou-se tecido TNT, que foram amarrados na $2^{\circ}$ bifurcação das espécies arbóreas, não sendo colocadas em fustes retilíneos como os indivíduos primeiramente introduzidos.

Os novos indivíduos de Aechmea bromeliifolia (Rudge) Baker foram dispostos aleatoriamente na área, com o objetivo de maximizar as condições ambientais, desta forma, obtendo-se resultados próximos das condições naturais.

\section{Avaliações realizadas}

O processo de avaliação (outubro/dezembro 2017) destes indivíduos consistiu na análise de 15 em 15 dias, totalizando três avaliações em 45 dias de experimento, de sobrevivência, analisando-se a quantidade de folhas e intensidade luminosa, por meio do aparelho Luxímetro Instrutherm LD-300. Foi realizada a irrigação dos indivíduos semanalmente, no fim da tarde, até o encerramento da estação seca.

A epífita foi considerada sobrevivente quando ainda possuía meristemas apicais ou outras gemas, sendo capaz de se desenvolver (emitir novas folhas, raízes, flores) e/ou de se reproduzir vegetativamente, ou morta, quando não mostrava mais qualquer forma de se desenvolver ou de gerar descendentes.

As reavaliações de sobrevivência foram realizadas de a fim de se verificar o desenvolvimento, registrando as seguintes informações: sobrevivência ou morte, continuidade de crescimento por meio do número de novas folhas e intensidade luminosa (Luxímetro).

Introdução dos novos indivíduos

\section{RESULTADOS E DISCUSSÃO}

A introdução de novos indivíduos na área experimental não demonstrou análise estatística significativa, em relação a luminosidade $x$ número de folhas, entre os forófitos de Caryocar brasilienses e Dipterex alata. Porém pode ser inferir que é possível a inserção de indivíduos de bromélias em áreas em processo de restauração, visto que não houve mortalidade.

A taxa de mortalidade das bromélias até a última avaliação era de $0 \%$, ou seja, não houve mortalidade. Contudo, na última avaliação foi possível a observação de duas bromélias que se apresentavam doentes devido a ação patogênica.

Embora não tenha sido encontrado diferença significativa no número de folhas para duas espécies hospedeiras, na Figura 01 são apresentados os resultados para Caryocar brasiliense Cambess. Pode se perceber que a $5^{\circ}$ bromélia apresentou o maior número de folhas, chegando a ter 10 folhas, enquanto a $3^{\circ}$ bromélia foi a única que não demonstrou desenvolvimento, porém não se encontrava morta. 


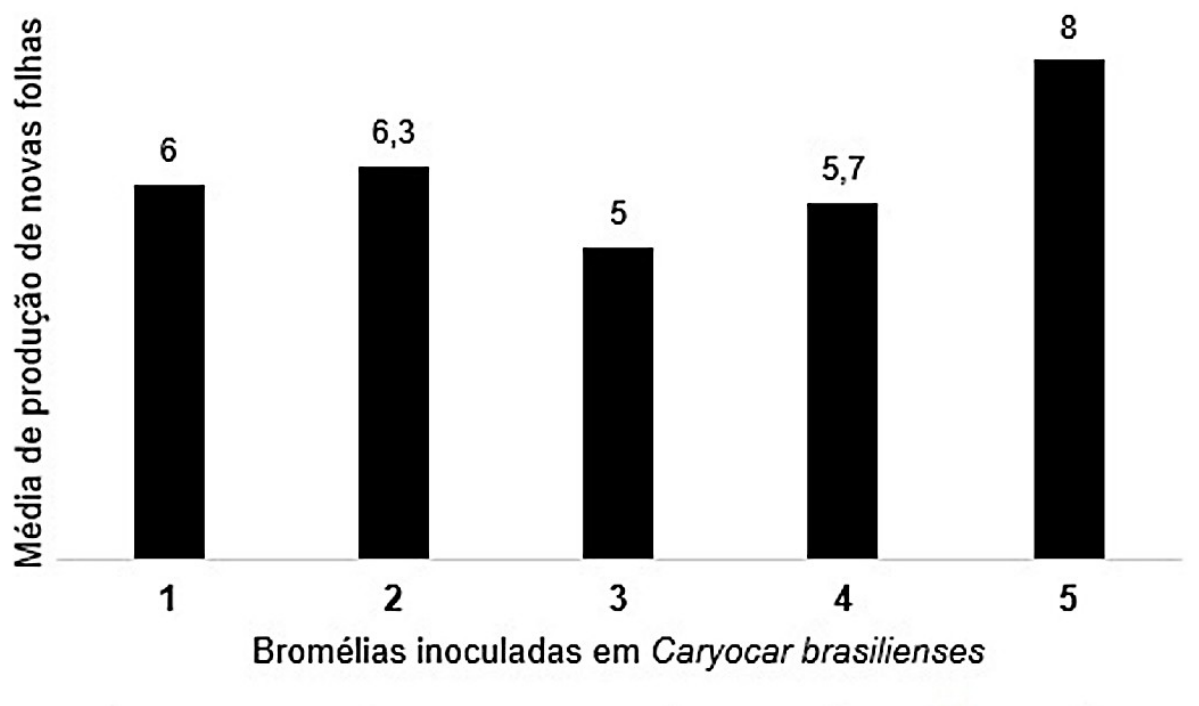

Figura 01. Produção médias de folhas da bromélia Aechmea bromeliifolia nas três avaliações realizadas no forófito Caryocar brasilienses.

De uma forma geral, os forófitos de Caryocar brasiliense Cambess se apresentaram como alternativa viável para a implantação e desenvolvimento da bromélia, não apresentando influências ou efeitos prejudiciais com a epífita.

A partir da mensuração da intensidade luminosa nos indivíduos de Caryocar brasiliense Cambess, percebeu-se que quanto maior a luminosidade, mais folhas as bromélias apresentavam, como demonstrado na Figura 02.

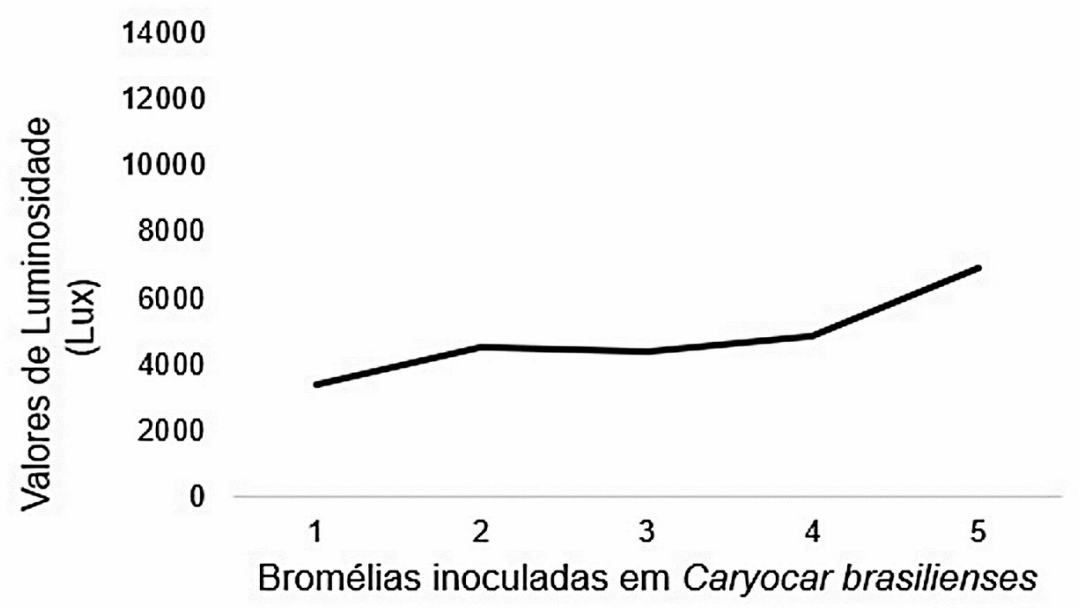

Figura 01. Luminosidade média (Lux) de Aechmea bromeliifolia em Caryocar brasiliense por bromélia introduzida.

Percebe-se que a $5^{\circ}$ bromélia apresentou a maior média de intensidade luminosa, sendo a que apresentou o maior número de folhas, demonstrando uma correlação. Portanto quanto maior a intensidade, maior o desenvolvimento, porém calculada a regressão, com a luz sendo variável independente, não foi significativa.

Trabalho realizado por Zimolong e Kruper (2019) com a bromélia Aechmea recurvata (Klotzsch) L. B. Sm. em um fragmento de floresta, encontrou diferença 
significativa no desenvolvimento das folhas nos indivíduos que recebiam maior intensidade luminosa, dessa forma, influenciando na taxa fotossintética.

Para Veloso e Klein (1957) a intensidade luminosa e a umidade relativa são os fatores de maior influência, tanto na distribuição quanto na abundância das espécies epifíticas. Para os indivíduos inoculados em Dipteryx alata Vogel, também se percebe, que este se apresenta como forófito viável para implantação e desenvolvimento das bromélias. Porém a produção no número de folhas foi inferior em relação ao Caryocar brasiliense Cambess, como demonstra a figura 03.

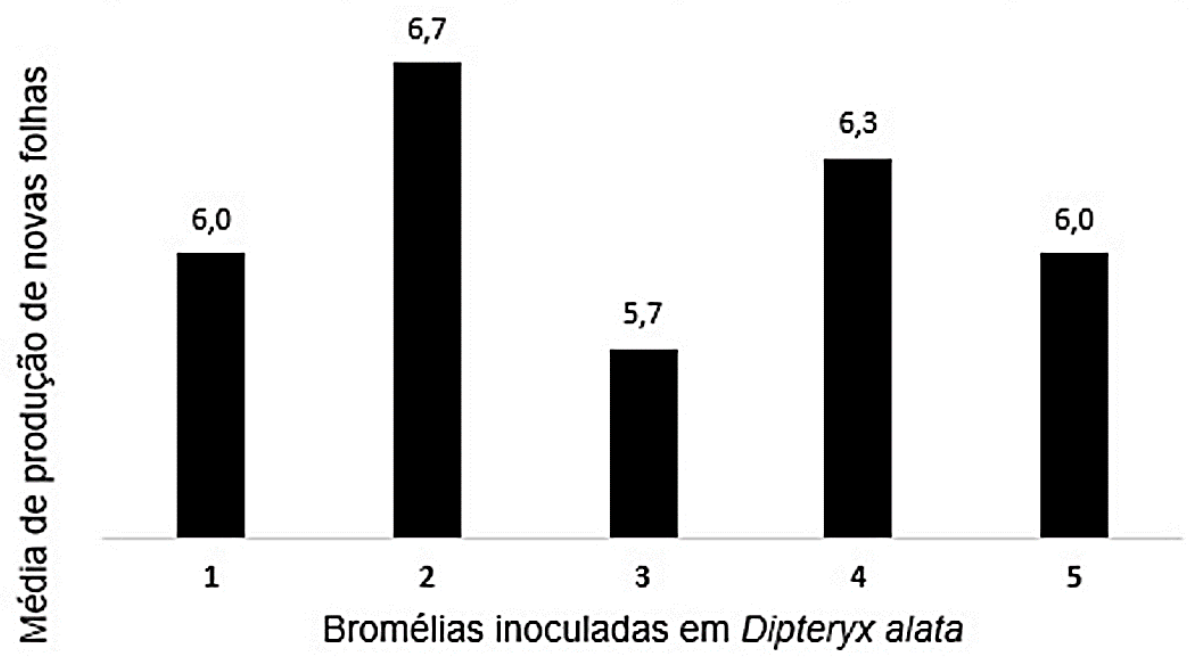

Figura 03. Número de folhas da bromélia Aechmea bromeliifolia nas três avaliações realizadas no forófito Dipteryx alata.

Como se percebe, a produção de folhas foi inferior aos indivíduos inoculados em Caryocar brasiliense Cambess, apresentando menores condições de adaptação para a epífita.

Não foi possível perceber uma correlação positiva entre intensidade luminosa e desenvolvimento no número de folhas para as epífitas inoculadas neste forófito, observado na Figura 04 . Sendo a $3^{\circ}$ bromélia que apresentou a maior média de intensidade luminosa, com a menor produção de folhas.

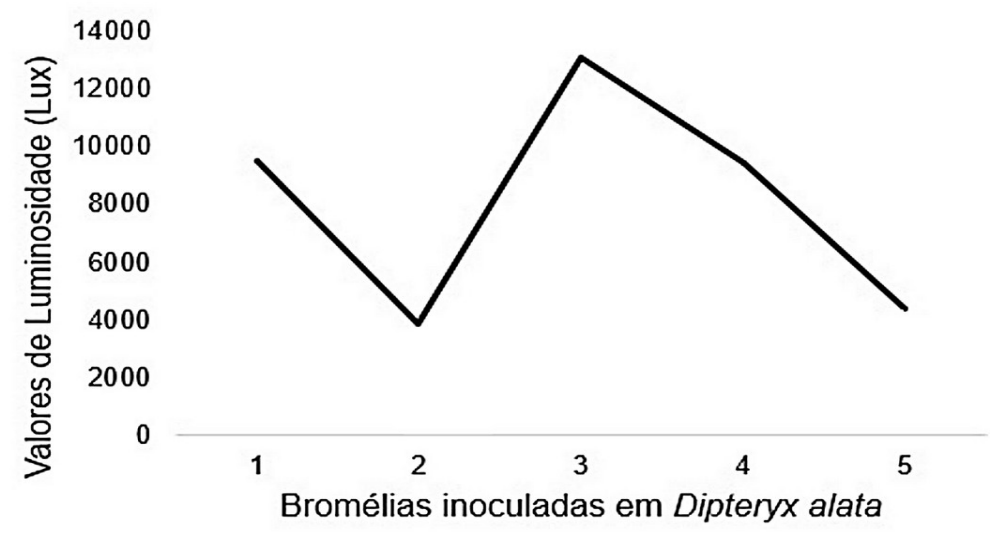

Figura 02. Luminosidade média dos indivíduos de Aechmea bromeliifolia em Dipteryx alata. 
Desta forma, não pode se afirmar que a intensidade luminosa interfere no desenvolvimento dos indivíduos da espécie, que tem comportamento generalista, pois para o desenvolvimento desta espécie, nestes forófitos, a variável luz não aparentou influenciar drasticamente no desenvolvimento.

Trabalho realizado no parque Witeck em Novo Cabrais - RS, estudando espécies epífitas em um fragmento em regeneração, também não encontraram correlação positiva entre os fatores abióticos (luz, temperatura e umidade) e o desenvolvimento das espécies quando comparados aos forófitos analisados (DE BORTOLI et al., 2017).

Isto pode estar relacionado a classificação dos grupos de Bromeliaceae em relação a intensidade luminosa. Pittendrigh (1948) propôs três grupos de plantas com diferentes preferências de luminosidade: o grupo de exposição ("exposure group"), de sol ("sun group") e tolerante a sombra ("shade-tolerant"). O grupo de exposição é composto por espécies que vivem em locais bem iluminados. Geralmente não suportam sombreamento porque os tricomas quando úmidos, podem bloquear a luz e impedir a troca gasosa. O grupo de sol, engloba aquelas que vivem em ambientes um pouco mais sombreados, possuem menos tricomas cobrindo a superfície das folhas. $\mathrm{E}$ as tolerantes à sombra, exigem maior umidade, e suas rosetas geralmente são mais abertas, com folhas mais finas, estreitas e compridas.

Isto parecer ser observado na área de estudo, pois as bromélias apresentam folhas compridas, rosetas abertas, e com o início do período chuvoso, aparentou maior desenvolvimento, devido ao aumento da umidade e disponibilidade de água. Portanto pode vir a ser que esta bromélia possa se enquadrar nos grupos tolerantes a sombra, porém necessita de mais trabalhos em ambientes naturais a fim de se afirmar este princípio.

Sabe-se que os forófitos influenciam no desenvolvimento das epífitas, principalmente na característica do fuste e copa das árvores. As características do substrato fornecido pelos forófitos, tais como textura, porosidade e persistência da casca, $\mathrm{pH}$, presença de toxinas e acúmulo de húmus são também fatores de relevância (TER STEEGE; CORNELISSEN, 1989).

O porte dos forófitos também influenciam o crescimento e instalação de novos indivíduos, sendo que, quanto maior as árvores, maior o número de colonização, porém mais estudos sobre a influência das condições abióticas são fundamentais no entendimento das relações ecológicas com os forófitos (JIMÉNEZ-LÓPEZ et al., 2017).

Composição florística realizada em floresta de savana no estado de São Paulo verificou que a abundância e riqueza de epífitas, estão relacionadas as características macro/microclimáticas dos locais, sendo que em estações com baixa precipitação a colonização é menor quando comparada as estações chuvosas, além de que, possivelmente a colonização de forófitos com tamanho maiores está relacionada a busca de melhores condições dos fatores ambientais, sendo as famílias Bromeliaceae e Polypodiaceae as que apresentaram maior número de espécies, 281 e 213, respectivamente (JOANITTI et al., 2017).

Desta forma, ambos os forófitos de Caryocar brasilienes e Dipterex alata se apresentam de forma eficientes para o desenvolvimento e perpetuação da espécie introduzida na área, mesmo não apresentando grande porte arbóreo.

As Bromeliáceas também são importantes fornecedoras de néctar para polinizadores vertebrados principalmente para espécies de morcegos e beija-flores, 
sendo uma das poucas famílias onde a polinização por vertebrados predomina sobre a entomofilia (SAZIMA, 1999).

Foi observado a presença de abelhas e outros insetos nas bromélias introduzidas, exemplificando um dos benefícios envolvidos na introdução de epífitas, a polinização e atração de fauna. Devido ao arranjos das suas folhas em espiral, a bromélia propicia a formação de diversos tanques que acumulam água e abrigam organismos de diversos gêneros, como Turbellaria spp., Nematoda spp., Oligochaeta spp., Crustracea (incluindo Elpidium sp.), Insecta, Arachnida, dessa forma estabelecendo associações benéficas, fornecendo maiores condições de umidade, sombreamento e proteção a altas temperaturas (FERNANDEZ BARRANCOS; REID; ARONSON, 2017; LOPEZ et al., 1998; OLIVEIRA; ROCHA, 2015; ROCHA et al., 2016).

Reavaliação dos indivíduos já implantados

Em relação aos indivíduos reavaliados, estes também foram introduzidos em diferentes localidades nas áreas, com os mesmos objetivos de aproximar as condições naturais. Porém foram introduzidos em troncos retilíneos e bifurcados, sempre na $1^{\circ}$ bifurcação.

A taxa de mortalidade dos indivíduos após um ano de implantação foi de $34 \%$, ou seja, dos 18 indivíduos introduzidos, somente 6 morreram, demonstrando efetivamente, o alto índice de adaptação e plasticidade desta espécie sob as condições impostas, principalmente ao clima tropical de Cerrado, com uma estação seca bem definida.

Quando se calcula a taxa de mortalidade por forófito, percebe-se que Jacaranda cuspidifolia Mart. foi o que não apresentou nenhuma morte, sendo os forófitos de Anadenanthera falcata e Sapindus saponaria L., com maiores taxas de mortalidade, apresentado na figura 05.

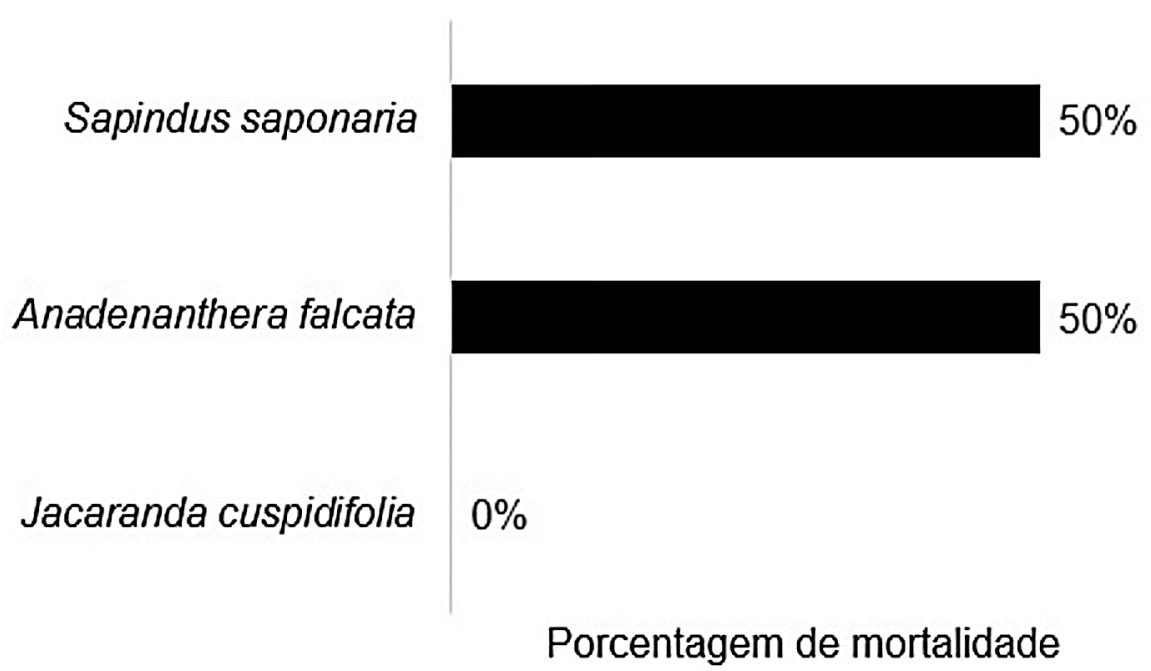

Figura 03. Taxa de mortalidade da bromelia Aechmea bromeliifolia nos forofitos Sapindus saponaria, Anadenanthera falcata e Jacaranda cuspidifolia.

Desta forma, percebe-se que a espécie de Jacarandá se apresenta como a mais eficiente para a introdução das bromélias. Sendo a que apresentou maiores produções e desenvolvimento no número de folhas ao longo de 1 ano, em relação as outras espécies apresentando na figura 06,07 e 08. 


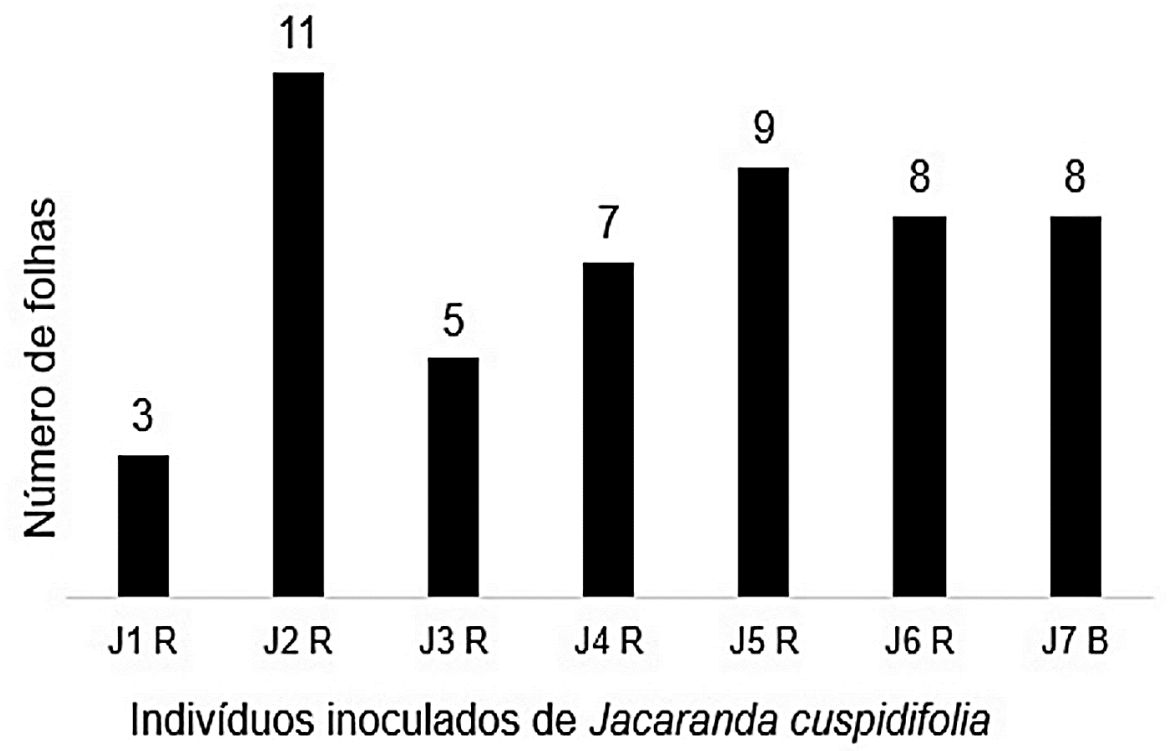

Figura 04. Número de folhas da bromélia Aechmea bromeliifolia nos forófitos de Jacaranda cuspidifolia Mart., em que $\mathrm{J}=\mathrm{Jacarandá,} \mathrm{B}=$ fuste bifurcado e R=fuste retilíneo.

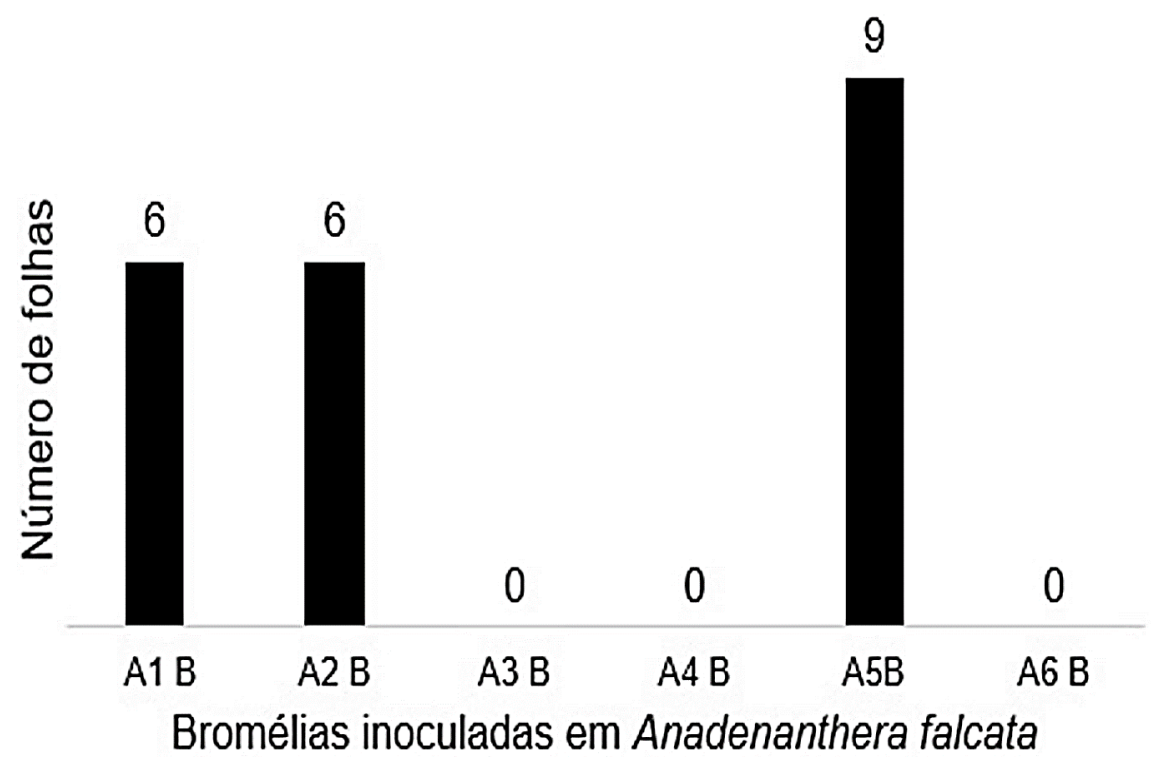

Figura 05. Número de folhas da bromélia Aechmea bromeliifolia nos forófitos de Anadenanthera falcata (Benth)., em que J=Jacarandá, B=fuste bifurcado e R=fuste retilíneo. 


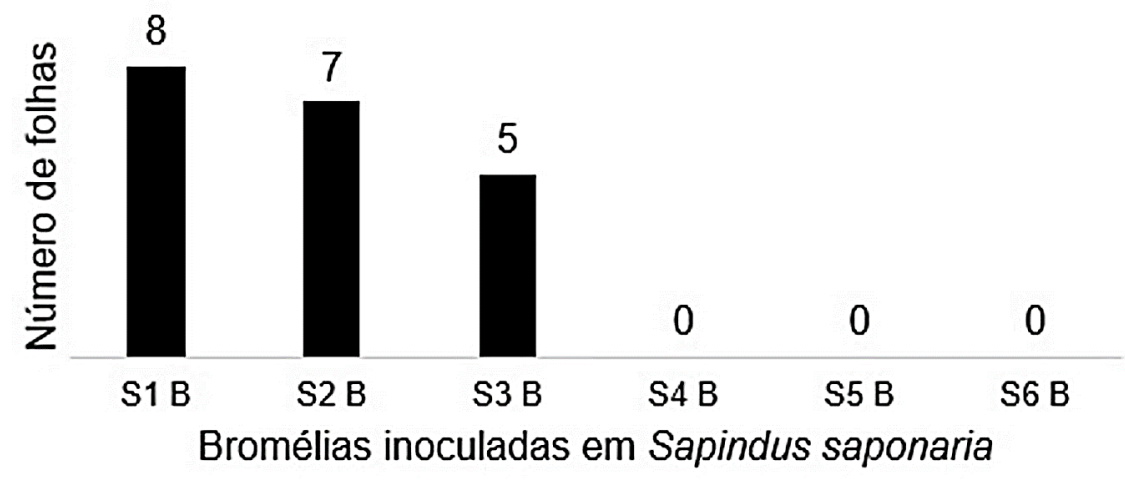

Figura 06. Número de folhas da bromélia Aechmea bromeliifolia nos forófitos de Sapindus saponaria L., em que $\mathrm{J}=$ Jacarandá, $\mathrm{B}=$ fuste bifurcado e $\mathrm{R}=$ fuste retilíneo.

Não foi encontrado correlação nenhuma entre a intensidade luminosa e o desenvolvimento no número de folhas das bromélias, como observado nos novos indivíduos introduzidos, demonstrando que esta espécie é tolerante a níveis de sombreamento, uma vez que, não aparenta desenvolvimento em maiores níveis de luminosidade.

Também não foi encontrado diferença entre os tipos de fuste, portanto, a espécie de bromélia se desenvolve tanto em fustes retilíneo quando em bifurcações. Foi encontrado bromélias em Jacaranda cuspidifolia Mart. em que, não se aparentava mais o tecido TNT de sustentação, sendo que as próprias raízes estavam desempenhando a ancoragem, como mostra a figura 09.

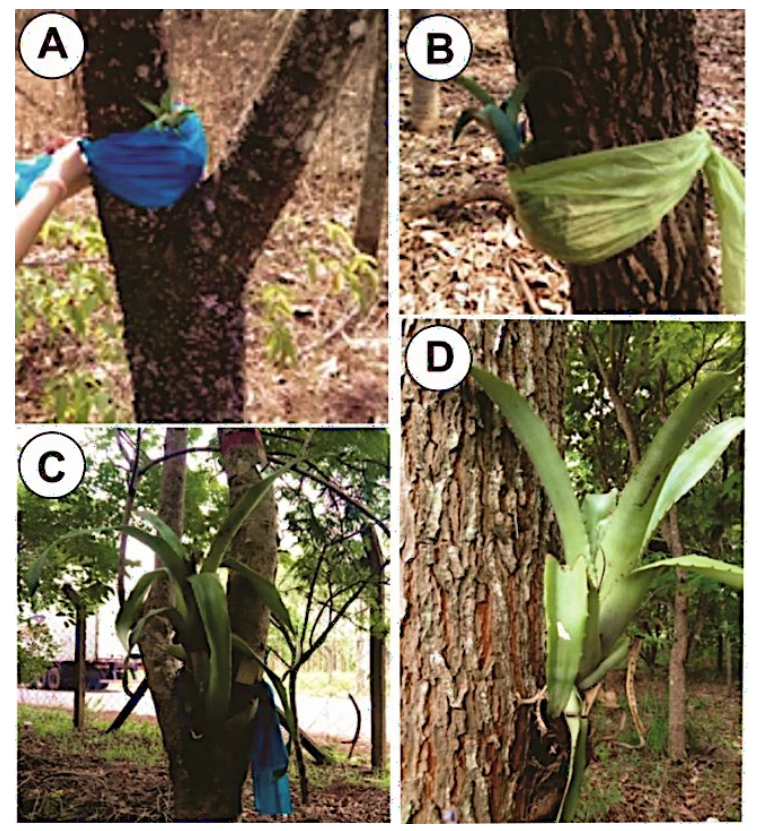

Figura 07. Bromélias de Aechmea bromeliifloia na implantação e no último dia de avaliação. A/B: Indivíduos de Aechmea bromeliifolia na implantação do experimento. C/D: Indivíduos de Aechmea bromeliifolia na última avaliação do experimento. 
Nas epífitas reavaliadas percebia-se que as folhas mortas eram decompostas nas próprias raízes das bromélias ou depositados no solo, contribuindo para a formação da serrapilheira, consequentemente a ciclagem de nutrientes.

Segundo Nadkarni e Matelson (1992), a redistribuição dos nutrientes estocados no material epifítico pode ser feita de diversos modos, como: a) pelo aporte de serrapilheira a partir da abscisão das suas folhas ou a partir da queda de galhos; b) diretamente ao hospedeiro via absorção por raízes adventícias e c) por herbívoria e predação por vertebrados e invertebrados.

As bromélias epífitas também interferem na ciclagem de nutrientes da floresta, que pela deposição de folhas nos estratos da serrapilheira contribuem para a liberação de nutrientes que podem ser incorporados ao solo. Trabalho realizado por Souza et al. (2016) estudando as espécies de bromélias Billbergia amoena, Neoregelia cruenta, Quesnelia quesneliana em florestas de restinga no Rio de Janeiro verificou presença significativa de grandes quantidades de folhas verdes das bromélias na serrapilheira, que armazenam nutrientes em concentrações decrescentes de K > N > P, sendo a Quesnelia quesneliana a bromélia com maiores concentrações.

Pode-se dizer que as bromélias exercem uma forte influência nos processos e manutenção dos ecossistemas. Desempenham importante papel como suporte à cadeia alimentar, utilizam de forma eficiente os nutrientes, disponibilizam água em suas imbricadas rosetas, redistribuindo desta forma, a umidade ao ambiente. Além disso, contribuem para a biodiversidade, com seu elevado número de espécies, e na produtividade e capacidade de resiliência dos ecossistemas (LUGO; SCATENA, 1992).

Zotz et al. (2020) ao analisar mais de 200 espécies de bromélias, constatou que elas podem armazenar entre 2 a $5000 \mathrm{~mL}$ de água externamente em seu tanque, sendo que quanto maior o indivíduo, maior a facilidade de armazenamento.

Amaral-Filho (2019) estudaram e encontraram que Parkia pendula que foi o forófito mais frequente e junto com Lecythis pisonis portaram $56 \%$ dos indivíduos das duas espécies de bromélias. Os resultados indicam um ambiente profundamente alterado por conta da fragmentação que se reflete na redução da riqueza de forófitos e bromélias no local. Barbosa et al. (2019) ressalta que o estado e conservação dos fragmentos influencia na diversidade de epífitas, cuja colonização se inicia por espécies holoepifítas.

O método de enriquecimento com epífitas ainda é pouco conhecido, porém trabalhos com esse objetivo veem demonstrando resultados promissores (DUARTE; GANDOLFI, 2017; FERNANDEZ BARRANCOS; REID; ARONSON, 2017).

A recuperação de bromélias em ambientes naturais ou em regeneração também já é registrado em literatura, sendo recomendado o plantio de espécies arbóreas próximos a regiões com cobertura florestal em altitudes elevadas (REID et al., 2016)

Perante isso, os forófitos de Jacaranca cuspidifoilia Mart., Caryocar brasiliense Cambess., Dipteryx alata Vogel, Sapindus saponaria L. e Anadenanthera falcata (Benth.) se apresentam como alternativas viáveis promovendo o desenvolvimento da bromélia Aechmea bromeliifolia (Rudge).

\section{CONCLUSÕES}

Após a realização do experimento pode-se constatar que a introdução de bromélias em áreas restauradas para fins de enriquecimento se mostra como uma 
alternativa viável para a introdução de um nível de biodiversidade assim como da formação de diversos extratos na área restaurada.

As bromélias apresentam importância no que se tange a ciclagem de nutrientes, interceptação da água proveniente de precipitações, abrigo para fauna, polinização e aumento da biodiversidade.

Não foi encontrado correlação entre a intensidade luminosa e o desenvolvimento no número de folhas da bromélia, indicando que esta pode apresentar tolerância ao desenvolvimento sombreado, necessitando de mais estudos em ambientes naturais.

Os forófitos de Jacaranda cuspidifolia Mart. são os que apresentaram melhor adaptação para esta espécie, seguido pela Caryocar brasiliense Cambess., Dipteryx alata Vogel, Sapindus saponaria L. e por fim Anadenanthera falcata (Benth), respectivamente.

\section{REFERÊNCIAS}

AMARAL-FILHO, J. D.; J.R., M. Estrutura de uma comunidade empobrecida de bromélias em uma paisagem hiper-fragmentada no Jardim Botânico do Recife-PE. Arrudea A revista do Jardim Botânico do Recife, v. 5, n. 1-2, p. 2-7, 2019. Disponível em: <http://arrudea.recife.pe.gov.br/arrudea/index.php/Arrudea/article/ view/25/52>.

BARBOSA, D. E. F.; BASILIO, G.A.; FURTADO, S.G.; MENINI, N. L. The Importance of Heterogeneity of Habitats for the species richness of vascular ephifytes in Remants of Brazilian montane seasonal semideciduos forest. Edinburgh Journal of Botany, p. 1-20, 16 out. 2019. Disponível em: <https://www.cambridge.org/core/product/identifier/S0960428619000313/type/ journal_article>.

BENZING, D. H. Vascular Epiphytes. [S.I.]: Cambridge University Press, 1990. Disponível em: <https://www.cambridge.org/core/product/identifier/9780511525438/type/book>.

CAVALCANTE, J. B. Meio ambiente e agricultura: uma análise sobre o cerrado brasileiro e as políticas para proteção ambiental. REVISTA ECONOMIA POLÍTICA DO DESENVOLVIMENTO, v. 9, n. 21, p. 80, 12 set. 2019. Disponível em: <http://www.seer.ufal.br/index.php/repd/article/view/8745>.

CURY, Roberta; JR, Oswaldo. Manual para restauração florestal: Florestas de Transição. Série BoaS ed. Belém: IPAM - Instituto de Pesquisa Ambiental da Amazônia, $2011 . \quad$ Disponível em: <https://www.researchgate.net/publication/296696631_Manual_para_restauracao_flo restal_Florestas_de_Transicao>.

DAROCHA, W. D.; RIBEIRO, S.P.; NEVES, F.S.; FERNANDES, G.S.; LEPOUNCE, M. et al. How does bromeliad distribution structure the arboreal ant assemblage (Hymenoptera: Formicidae) on a single tree in a Brazilian Atlantic forest agroecosystem? Myrmecological News, v. 21, p. 83-92, 2015. Disponível em: $<$ https://myrmecologicalnews.org/cms/index.php?

option=com_content\&view=category\&id=617\&ltemid=365>. 
DE BORTOLI, J.; BECKEL, H.D.J; LAPPE, E.; BRUXEL, M.; BERNADES, B.J.R. et al. Estudo de caso sobre diversidade e abundância de epífitas sobre forófitos de borda de fragmento do parque Witeck, Novo Cabrais - RS. Caderno de Pesquisa, v. 29, n. 2, 52 maio 2017.2 Disponível em: <https://online.unisc.br/seer/index.php/cadpesquisa/article/view/9796>.

DUARTE, M. M.; GANDOLFI, S. Diversifying growth forms in tropical forest restoration: enrichment with vascular epiphytes. Forest Ecology and Management, v. 401, p. 89-98, 2017. Disponível em: <https://repositorio.usp.br/item/002843672>.

FERNANDEZ BARRANCOS, E. P.; REID, J. L.; ARONSON, J. Tank bromeliad transplants as an enrichment strategy in southern Costa Rica. Restoration Ecology, v. 25, n. 4, p. 569-576, jul. 2017. Disponível em: <http://doi.wiley.com/10.1111/rec.12463>.

FORZZA, R. C.; COSTA, A.; SIQUEIRA FILHO, J. A.; MARTINELLI, G.; MONTEIRO, R. F. et al. Bromeliaceae In Lista de Espécies da Flora do Brasil. Jardim Botânico do Rio de Janeiro. (http://floradobrasil.jbrj.gov.br/jabot/floradobrasil/FB66) acesso em 08/01/2016.

GERBER, D.; JUNIOR, A.W.; PERTILLE, C.T.; LUBKE, L.; LUBKE, M. et al. Utilização de Bromelia antiacantha Bertol. em projetos de restauração ecológica. Acta Biológica Catarinense, v. 4, n. 2, 8 nov. 2017. Disponível em: $<$ ttp://periodicos.univille.br/index.php/ABC/article/view/392h>.

JIMÉNEZ-LÓPEZ, D. A.; ROBLERO-VELASCO, R.D.N.; MARTINEZ-MELENDEZ, N.O.; GALLARDO-CRUZ, J.A. Relación entre variables del forófito y la riqueza de epífitas vasculares en los Pantanos de Centla, Tabasco, México. Acta Botanica Mexicana, n. 121, p. 125-137, 2 out. 2017. Disponível em: <http://abm.ojs.inecol.mx/ index.php/abm/article/view/1179>.

JOANITTI, S. A.; VERIDIANA, L.W.; OSMAR, A.L. Vascular epiphytes in a woodland savanna forest in southeastern Brazil. The Journal of the Torrey Botanical Society, v. 144, n. 4, p. 439-449, out. 2017. Disponível em: <http://www.bioone.org/ doi/10.3159/TORREY-D-16-00029.1>.

LOPEZ, L.C.S.; D'ELIAS, A.M.A; IGLIESIS, R.R. Fatores que controlam a riqueza e a composição da fauna aquática em tanques da bromélia aechmea bromeliifolia (Rudge) Baker, na restinga de Jacarepiá - Saquarema / RJ. Oecologia Brasiliensis, v. 5, p. 91-100, 1998. Disponível em: <https://dialnet.unirioja.es/servlet/articulo? codigo $=2886020>$.

LUGO, A. E.; SCATENA, F. N. EPIPHYTES AND CLIMATE CHANGE RESEARCH IN THE CARIBBEAN: A PROPOSAL. Selbyana, v. 13, p. 123-130, 1992. Disponível em: <http://www.jstor.org/stable/41759801>.

MAGNAGO, L. F. S.; MARTINS, S. V.; SCHAEFER, C.E.G.R.; NERI, A. V. Restinga forests of the Brazilian coast: richness and abundance of tree species on different soils. Anais da Academia Brasileira de Ciências, v. 84, n. 3, p. 807-822, set. 2012. Disponível em: <http://www.scielo.br/scielo.php?script=sci_arttext\&pid=S0001- 
$37652012000300023 \&$ Ing=en\&tlng=en>.

MONTANA, C.; DIRZO, R.; FLORES, A. Structural Parasitism of an Epiphytic Bromeliad upon Cercidium praecox in an Intertropical Semiarid Ecosystem. Biotropica, v. 29, n. 4, p. 517-521, dez. 1997. Disponível em: $<$ http://doi.wiley.com/10.1111/j.1744-7429.1997.tb00046.x>.

MOLIZANE, D. M.; KANASHIRO, S.; TAVARES, A.R.; BARBEDO, C.J. Maturação de sementes de Aechmea bromeliifolia (Rudge) Baker e Vriesea paraibica Wawra (Bromeliaceae). Hoehnea, v. 40, n. 4, p. 619-625, dez. 2013. Disponível em: <http:// www.scielo.br/scielo.php?script=sci_arttext\&pid=S2236-

$89062013000400005 \&$ Ing $=p t \& t \mid n g=p t>$.

NADKARNI, N. M.; MATELSON, T. J. Biomass and Nutrient Dynamics of Epiphytic Litterfall in a Neotropical Montane Forest, Costa Rica. Biotropica, v. 24, n. 1, p. 24, mar. 1992. Disponível em: <https://www.jstor.org/stable/2388470?origin=crossref>.

OLIVEIRA, J. C. F.; ROCHA, C. F. D. Journal of coastal conservation: a review on the anurofauna of Brazil's sandy coastal plains. How much do we know about it? Journal of Coastal Conservation, v. 19, n. 1, p. 35-49, 22 fev. 2015. Disponível em: <http://link.springer.com/10.1007/s11852-014-0354-8>.

PITTENDRIGH, C. S. THE BROMELIAD-ANOPHELES-MALARIA COMPLEX IN TRINIDAD. I-THE BROMELIAD FLORA. Evolution, v. 2, n. 1, p. 58-89, mar. 1948. Disponível em: <http://doi.wiley.com/10.1111/j.1558-5646.1948.tb02732.x>.

REID, J. L.; CHAVES-FALLAS, J.M.; HOLL, K.D.; ZAHAMI, R.A. Tropical forest restoration enriches vascular epiphyte recovery. Applied Vegetation Science, v. 19, n. 3 , p. 508-517, jul. 2016. Disponível em: <http://doi.wiley.com/10.1111/avsc.12234>.

ROCHA, W. D.; NEVES, S.F.; DATTILO, W.; DELABIE, J.H.C. Epiphytic bromeliads as key components for maintenance of ant diversity and ant-bromeliad interactions in agroforestry system canopies. Forest Ecology and Management, v. 372, p. 128136, jul. $2016 . \quad$ Disponível em: $<$ https://linkinghub.elsevier.com/retrieve/pii/S0378112716301670>.

SAZIMA, M. Bat-pollinated Flower Assemblages and Bat Visitors at Two Atlantic Forest Sites in Brazil. Annals of Botany, v. 83, n. 6, p. 705-712, jun. 1999. Disponível

em:

<https://academic.oup.com/aob/article-lookup/doi/10.1006/anbo.1999.0876>.

SILVA, E. C.; SIBOV, S.T.; SANTOS, F.C.A.; GONÇALVES, L.A. Influence of test tube sealing on the morpho-anatomy and ultrastructure of leaves of Aechmea bromeliifolia (Bromeliaceae) grown in vitro. Rodriguésia, v. 71, 2020. Disponível em: $<$ http://www.scielo.br/scielo.php?script=sci_arttext\&pid=S217578602020000100204\&tlng=en>.

SOUZA, R.C.; PEREIRA, M.J.; MENEZES, L.F.T.; SILVEIRA FILHO, T.B.; SILVA, A.N. Role of Terrestrial Bromeliads in Nutrient Cycling, Restinga da Marambaia, 
Brazil. Floresta e Ambiente, v. 23, n. 2, p. 161-169, 23 fev. 2016. Disponível em: $<$ http://www.scielo.br/scielo.php?script=sci_arttext\&pid=S2179-

$80872016000200161 \&$ Ing=en\&tlng=en>.

TER STEEGE, H.; CORNELISSEN, J. H. C. Distribution and Ecology of Vascular Epiphytes in Lowland Rain Forest of Guyana. Biotropica, v. 21, n. 4, p. 331, dez. 1989. Disponível em: <https://www.jstor.org/stable/2388283?origin=crossref $>$.

VELOSO, H. P.; KLEIN, R. M. As comunidades e associações vegetais da mata pluvial atlântica do sul do Brasil. I. As associações no município de Brusque, Estado de Santa Catarina. Sellowia, v. 8, p. 81-235, 1957.

ZOTZ, G.; LEJA, M.; AGUILAR-CRUZ, Y.; EINZMANN, H.J.R. How much water is in the tank? An allometric analysis with 205 bromeliad species. Flora, v. 264, p. 151557, mar. 2020 Disponível em: <https://linkinghub.elsevier.com/retrieve/pii/S0367253020300219>.

ZIMOLONG, R.; KRUPEK, R. A. Aechmea recurvata (Klotzsch) L. B. Sm. (Bromeliaceae) em um fragmento de floresta ombrófila mista. Acta Biológica Catarinense, v. 6, n. 2, p. 42-51, 2019. Disponível em: <http://186.237.248.25/index.php/ABC/article/view/441/648>. 